\title{
Inhibitory effects of sodium pentosan polysulfate on formation and function of osteoclasts derived from canine bone marrow
}

H. M. Suranji Wijekoon * D, Eugene C. Bwalya, Jing Fang, Sangho Kim, Kenji Hosoya and Masahiro Okumura

\begin{abstract}
Background: Sodium pentosan polysulfate (NaPPS) was testified as a chondroprotective drug in with a detailed rationale of the disease-modifying activity. This study was undertaken to determine whether anti-osteoarthritis drug, NaPPS inhibited osteoclasts (OC) differentiation and function. Canine bone marrow mononuclear cells $(n=6)$ were differentiated to $\mathrm{OC}$ by maintaining with receptor activator of nuclear factor kappa B ligand (RANKL) and macrophage colony-stimulating factor (M-CSF) for up to 7 days with the treatment of NaPPS at concentration of 0, 0.2, 1 and $5 \mu \mathrm{g} / \mathrm{mL}$. Differentiation and function of OC were accessed using tartrate-resistant acid phosphate (TRAP) staining and bone resorption assay, while monitoring actin ring formation. Invasion and colocalization patterns of fluorescence-labeled NaPPS with transcribed gene in OC were monitored. Gene expression of OC for cathepsin K (CTK), matrix metallopeptidase-9 (MMP-9), nuclear factor of activated T-cells cytoplasmic 1 (NFATC1), c-Fos, activator protein-1 (AP-1) and carbonic anhydrase II was examined using real-time PCR.

Results: Significant inhibition of OC differentiation was evident at NaPPS concentration of 1 and $5 \mu \mathrm{g} / \mathrm{mL}(p<0.05)$. In the presence of 0.2 to $5 \mu \mathrm{g} / \mathrm{mL} \mathrm{NaPPS}$, bone resorption was attenuated $(p<0.05)$, while 1 and $5 \mu \mathrm{g} / \mathrm{mL} \mathrm{NaPPS}$ achieved significant reduction of actin ring formation. Intriguingly, fluorescence-labeled NaPPS invaded in to cytoplasm and nucleus while colocalizing with actively transcribed gene. Gene expression of CTK, MMP-9 and NFATc1 were significantly inhibited at 1 and $5 \mu \mathrm{g} / \mathrm{mL}(p<0.05)$ of NaPPS whereas inhibition of c-Fos and AP-1 was identified only at concentration of $5 \mu \mathrm{g} / \mathrm{mL}(p<0.05)$.

Conclusions: Taken together, all the results suggest that NaPPS is a novel inhibitor of RANKL and M-CSF-induced CTK, MMP-9, NFATC1, C-FOS, AP-1 upregulation, OC differentiation and bone resorption which might be a beneficial for treatment of inflammatory joint diseases and other bone diseases associated with excessive bone resorption.
\end{abstract}

Keywords: Sodium pentosan polysulfate, Osteoclast differentiation, Bone marrow, Bone resorption, Dog

\section{Background}

Bone homeostasis is crucial to maintain the integrity of bone functions that coordinates balance between bone resorption by osteoclasts $(\mathrm{OC})$ and bone formation by chondrocytes/osteoblasts $[1,2]$. It is well established that an imbalance in the function of $\mathrm{OC}$ and osteoblasts has severe consequences for the organism, leading to serious

\footnotetext{
* Correspondence: suranjisk@gmail.com

Department of Veterinary Clinical Sciences, Laboratory of Veterinary Surgery,

Graduate School of Veterinary Medicine, Hokkaido University, Sapporo
} 060-0818, Japan

(c) The Author(s). 2018 Open Access This article is distributed under the terms of the Creative Commons Attribution 4.0 International License (http://creativecommons.org/licenses/by/4.0/), which permits unrestricted use, distribution, and

reproduction in any medium, provided you give appropriate credit to the original author(s) and the source, provide a link to the Creative Commons license, and indicate if changes were made. The Creative Commons Public Domain Dedication waiver (http://creativecommons.org/publicdomain/zero/1.0/) applies to the data made available in this article, unless otherwise stated.

bone pathologies such as osteoporosis, joint and bone diseases involving the immune system including, rheumatoid arthritis (RA) and periodontal disease [3]. Osteoclasts, which originate from monocyte/macrophage lineage from bone marrow hematopoietic precursors [4] are the principal multinucleate giant resorptive cells of bone. Two major factors such as macrophage colony-stimulating factor (M-CSF) and receptor activator of NF kappa B ligand and (RANKL) are required for their differentiation and maturation [5-7]. Receptor activator of NF kappa B ligand binds to its receptor, receptor activator of NF kappa B on 
OC precursors [8], which involve the activation of NF-kB and Jun $\mathrm{N}$-terminal kinase, eventually leading to the expression of activator protein-1 (AP1)/ Fos, an essential regulator of OC differentiation [9]. Previously reports have shown that $\mathrm{OC}$ precursors are found in both peripheral blood and synovial tissues of human with RA [10, 11]. Osteoclast precursors which are unable to resorb bone [12] stained positive for tartrate-resistant acid phosphatase (TRAP) eventually fuse to form multinucleated mature TRAP-positive OC [13]. Thus maturation and functional capability of OC while differentiation, are critical cellular process, understanding its regulation will have an important impact on the development of a new therapy to control bone loss among human and dogs.

In the past few years, the concept of disease -modifying osteoarthritis drugs (DMOADs) have been explored as an alternative treatment modality for osteoarthritis (OA) [14] instead of using nonsteroidal antiinflammatory drugs (NSAIDs) which has been frequently used for treating OA and associate with a high risk for gastrointestinal lesions with long-term uses [15]. Sodium pentosan polysulfate (NaPPS) is a semi-synthetic sulfated polysaccharide drug manufactured from European beechwood hemicellulose by sulfate esterification with the average molecular weight of $5700 \mathrm{Da}$ [16]. From the results of previous in vitro and in vivo studies, the spectrum of pharmacological activities exhibited by NaPPS would qualify it as DMOADs [17] because of its ability to preserve the integrity of the articular cartilage and bone while improving the quality of the joint synovial fluid [18-21].

Although PPS has been used for a number of years for the treatment of thrombotic and hyperlipidemic indications [20] it has only recently been shown to be effective in improving the symptoms of human patients with OA [16]. While the molecular mechanism of PPS action at the microenvironment of joint remains unclear, some previous reports show that, NaPPS is capable in enhancing synthesis of proteoglycans such as aggrecan, which is intimately associated with resist compression throughout the extracellular matrix of articular cartilage [22]. Hence, synovial changes in dogs with canine arthritis mimic human RA, dogs are the potential useful model for studies of therapy [23]. Recently, it has been reported that NaPPS can inhibit osteogenic differentiation in human bone marrow derived precursor cells while inducing chondrogenic differentiation from bone marrow-derived mesenchymal stem cells in canine as well as human $[24,25]$. Use of progenitor cells origin from different sources is being used for investigating the therapeutic effects and to imply its clinical uses [26]. However, among the several previous human and animal studies of NaPPS based on cartilage research, there was dearth of information on effect of NaPPS over the osteoclastogenesis, anti-resorptive capability and influence on cell signaling molecules of OC. To the best of our knowledge, present study is the first attempt to identify the interaction of NaPPS with in vitro cultured OC-derived from dog bone marrow. The objective of the study reported here was to determine whether there was an effect of NaPPS on osteoclastogenesis of canine bone marrow-derived hematopoietic precursor cells. We hypothesized that the NaPPS, which carry different effect by improving the symptoms of OA would more likely to have an inhibitory effect on OC differentiation and its signaling pathways.

\section{Methods}

Osteoclastic differentiation from canine bone marrow

Proximal femur of one year old, healthy beagle dogs $(n=$ 6) were used to collect the $5 \mathrm{~mL}$ of bone marrow samples in to $10 \mathrm{~mL}$ syringe containing $1 \mathrm{~mL}$ Dulbecco's modified eagle's medium (DMEM, Life technologies, New York, USA) and $1000 \mathrm{U} / \mathrm{mL}$ of heparin (Nipro, Osaka, Japan). The use of all samples from healthy experimental dogs was in accordance with Hokkaido University Institutional Animal Care and Use Committee guidelines (approval number: 12-0059). Separation of bone marrow mononuclear cell (BMMs) fraction was done and preceded as described previously [27, 28]. Briefly, BMMs was obtained by density gradients centrifugation over lymphoprep (Axis-sheild PoC AS, Oslo, Norway) to remove red blood cells. Isolated BMMs cell fraction $\left(5 \times 10^{6}\right.$ cells $\left./ \mathrm{mL}\right)$ was incubated with DMEM containing penicillin/streptomycin (100 units/mL, Wako pure chemical, Tokyo, Japan) and $10 \%$ heat-inactivated fetal bovine serum (FBS, Nichirei Bioscience INC., Tokyo, Japan) for $24 \mathrm{~h}$ to separate the non-adherent and adherent cells. Non-adherent were collected as a source of immature OC precursors, suspended in DMEM, counted, seeded on 48-well plates (Corning, New York, USA) at $2 \times 10^{5}$ cells/well, and cultured in DMEM with the presence of $20 \mathrm{ng} / \mathrm{ml}$ recombinant human M-CSF (Invitrogen, Maryland, USA) for 3 days. After 3 days, adherent cells were used as OC precursors after washing out the non-adherent cells, including lymphocytes and further cultured in the presence of $25 \mathrm{ng} / \mathrm{mL}$ M-CSF, $50 \mathrm{ng} / \mathrm{mL}$ recombinant human RANKL (Sigma-Aldrich, St Louis, Missouri, USA) to generate osteoclast-like multinucleated giant cells. The cells were treated with $0,0.2,1$ and $5 \mu \mathrm{g} / \mathrm{mL}$ concentration of NaPPS (Cartrophen Vet-Biopharm-100 mg/ $\mathrm{ml}$, New South Wales, Australia) for 1-week. The selected concentrations of NaPPS are within the previous proved non-cytotoxic range for bone marrow derived cells [24]. Triplicate cultures for each concentration of NaPPS were maintained by changing the media in every $48 \mathrm{~h}$ ensuring their constancy of concentrations. 
Tartrate-resistant acid phosphate (TRAP) staining

Cultured BMMs with M-CSF and RANKL in the presence or absence of NaPPS were subjected to TRAP stain (Cosmo Bio Co., LTD, Tokyo, Japan) after 7 days. Cells were washed with $1 \%$ phosphate buffered saline (PBS) and fixed with $10 \%$ formalin neutral buffer solution for $5 \mathrm{~min}$ at room temperature. After washing with $500 \mu \mathrm{L}$ deionized water 3 times, cells were stained for TRAP according to the manufacturer's instructions. Cells containing $\geq 3$ nuclei were considered as $\mathrm{OC}$ and counted.

\section{Pit formation assay}

Non-adherent cells, collected from BMMs fraction of 3 dogs were cultured at $2 \times 10^{5}$ cells/well density on bone resorption assay plate 48 (PG Research, Tokyo, Japan) which was coated with calcium phosphate (CaP-coated). The cells were maintained in DMEM with the presence of $20 \mathrm{ng} / \mathrm{ml}$ recombinant human M-CSF (Invitrogen, Maryland, USA) for 3 days in triplicate cultures. After 3 days, adherent cells were used as OC precursors after washing out the non-adherent cells and further cultured in the presence of $25 \mathrm{ng} / \mathrm{mL}$ M-CSF, $50 \mathrm{ng} / \mathrm{mL}$ recombinant human RANKL and NaPPS at various concentrations $(0,0.2,1$ and $5 \mu \mathrm{g} / \mathrm{mL})$. After 7 days, the CaP-coated plate was treated with $5 \%$ sodium hypochlorite (Sigma-Aldrich, St Louis, Missouri, USA) for 5 min according to the manufacturer's instructions. The resorption pit area was analyzed and counted by Image-J software (Image J software version 1.43, National Institute of Health).

\section{Actin ring formation assay}

The actin ring formation assay was performed as described previously [29]. Briefly, BMMs cultured with M-CSF, RANKL and various concentrations of NaPPS for 7 days were washed with PBS and fixed with $4 \%$ paraformaldehyde (Wako pure chemical, Tokyo, Japan) in PBS on ice for $20 \mathrm{~min}$. Osteoclasts were detergent-permeabilized with $0.2 \%$ Triton X-100 (ICN Biomedicals, Germany) in PBS for $10 \mathrm{~min}$, washed and blocked in 10\% normal goat serum (Sigma-Aldrich, St Louis, Missouri, USA) in PBS for $1 \mathrm{~h}$. The cells were incubated with primary rabbit anti-F actin polyclonal antibody (Bioss Inc., Massachusetts, USA) (1:100 dilution) for $1 \mathrm{~h}$ in PBS with $1 \%$ normal goat serum, washing three times with PBS, incubating for $1 \mathrm{~h}$ with fluorescein isothiocyanate (FITC)-conjugated goat anti-rabbit antibody (Sigma) (1:100 dilution) in PBS with $1 \%$ normal goat serum, washing three times with PBS, and finally mounting with aqueous mounting medium. The images were observed by counting the number of actin rings under a laser scanning confocal microscope (Zeiss, Illinois, USA).

\section{Immunocytochemical detection of localization of NaPPS} with actively transcribed gene

Osteoclast precursors resulting from canine bone marrow cells $\left(2 \times 10^{5}\right.$ cells $)$ were cultured in 8 -well culture slide (Iwaki, Tokyo, Japan) in $400 \mu \mathrm{L}$ of DMEM, $10 \%$ FBS with OC differentiation factors. Cells were incubated with $10 \mu \mathrm{g} / \mathrm{mL}$ of Tetramethylrhodamine (TRITC)-labeled NaPPS (Arthropharm, New South Wales, Australia) for $24 \mathrm{~h}$. After fixation and blocking, cells were incubated with primary anti-human c-Jun (HT-9) rabbit polyclonal antibody (Santa Cruz Biotechnology, Dallas, Texas, USA) (1:100 dilution) in 1\% normal goat serum followed by incubation with FITC-conjugated goat anti-rabbit antibody (Sigma) (1:100 dilution) in 1\% normal goat serum. The OC were observed for detecting the colocalization patterns of NaPPS with transcribed gene (c-Jun) under a laser scanning confocal microscope.

\section{mRNA isolation and RT-PCR}

Total RNA from cells was extracted using RNeasy Mini Kit (QIAGEN, Germantown, Maryland, USA) according to the manufacture's protocol. Total RNA was quantified by spectrophotometry at $260 \mathrm{~nm}$. RNA with a $260 / 280 \mathrm{~nm}$ ratio in the range 1.8-2.0 was considered high quality and then transcribed into cDNA with M-MLV RT kit (Takara Bio, Tokyo, Japan) according to manufacturer's recommended procedures. One microgram of total RNA derived was reverse-transcribed into cDNA with random hexamers. PCR conditions were as follows: denaturation at $95{ }^{\circ} \mathrm{C}$ for $30 \mathrm{~s}$, annealing temperature for $1 \mathrm{~min}$, extension at $72{ }^{\circ} \mathrm{C}$ for $1 \mathrm{~min}$ for 30 cycles, and final extension at $72{ }^{\circ} \mathrm{C}$ for $7 \mathrm{~min}$. PCR products were separated on $1.5 \%$ agarose gel (BM Equipment, Tokyo, Japan) and stained with ethidium bromide (Nippon Gene, Tokyo, Japan).

\section{Real-time PCR}

Quantitative real-time PCR analysis was performed with KAPA SYBR ${ }^{\circ}$ FAST qPCR kit (KAPA). The amount of $2 \mu \mathrm{L}$ of cDNA template was added to each $10 \mu \mathrm{L}$ of premixture with specific primers. The following primer sets were used: carbonic anhydrase II (CAII), 5'-AAGG AGCCCATCAGCGTTAG-3' (forward) and 5'-GGGCG CCAGTTATCCATCAT-3' (reverse); NFATc1, 5'-CAC AGGCAAGACTGTCTCCA-3' (forward) and 5'-TCCT CCCAATGTCTGTCTCC-3' (reverse); MMP-9, 5'-GG CAAATTCCAGACCTTTGA-3' (forward) and 5'-TAC ACGCGAGTGAAGGTGAG-3' (reverse); c-Fos, 5' - GT CCGTACAGACCACAGACC-3' (forward) and 5'-CGC TCCACTTCATTGTGCTG-3' (reverse); CTK, 5' - ACC CATATGTGGGACAGGAT-3' (forward) and 5'-TGGA AAGAGGTCAGGCTTGC-3' (reverse); AP-1, 5'-TCTA CGACGATGCCCTCAAC-3' (forward) and 5'-TGAGCA GGTCCGAGTTCTTG-3' (reverse); GAPGH, 5'CTGA ACGGGAAGCTCACTGG-3' (forward) and 5'-CGATG 
CCTGCTTCACTACCT-3' (reverse). All reactions were normalized to the housekeeping gene b-Actin. glyceraldehyde-3-phosphate dehydrogenase (GAPDH).

\section{Statistical analysis}

Quantitative real-time PCR data, number of OC, resorption pits and actin rings were analyzed using SPSS software (SPSS software ver. 07 for Windows; SPSS Inc., Chicago, Illinois, USA). Analysis of variance (ANOVA) was used to compare the mean values between the treatments. Where significant different observed, multiple comparison of group means was performed using Post Hoc Bonferroni. Significant level was defined as $p<0.05$. All quantitative results are presented as mean $\pm \mathrm{SE}$.

\section{Results}

The effect of different concentration of NaPPS on OC differentiation from BMMs stimulated with RANKL and M-CSF was evaluated. The number of TRAP-positive multinuclear cells ( $\geq 3$ nuclei) generated in 48 well plate were reduced with the administration of NaPPS at the concentration of 1 and $5 \mu \mathrm{g} / \mathrm{mL} \mathrm{NaPPS}(p<0.05)$ (Fig. 1a, b). Osteoclast specific genes, CAII, CTK and MMP-9 expression were analyzed after treatment of $\mathrm{NaPPS}$ at the concentration of $0.2,1$ and $5 \mu \mathrm{g} / \mathrm{mL}$. Relative mRNA expression level of CTK and MMP-9 genes were significantly downregulated $(p<0.05)$ at 1 and $5 \mu \mathrm{g} / \mathrm{mL}$ concentrations of NaPPS (Fig. 1c, d, e).

$\mathrm{NaPPS}$ on bone resorption was assessed with OC generated from 3 dogs. Cells were plated on CaP-coated plates and stimulated with M-CSF and RANKL in the presence or absence of NaPPS. Cells stimulated with M-CSF and RANKL formed a number of resorption pits (Fig. 2a, b), suggesting that the bone resorption activity of RANKL-treated cells made them into functionally active state resembling OC. All the concentrations of NaPPS $(0.2,1$ and $5 \mu \mathrm{g} / \mathrm{mL})$ significantly reduced the formation of resorption pits in number and in overall area compared with treatment with M-CSF and RANKL alone. In the presence of RANKL exposure, BMMs can differentiate into mature $\mathrm{OC}$ and form distinct actin-ring structures (Fig. 2c, d). However, NaPPS significantly reduced the number of actin-ring structures at 1 and $5 \mu \mathrm{g} / \mathrm{mL}$ concentrations, suggesting the inhibitory effect of certain concentration of NaPPS over the functional unit of OC.

Canine OC were treated with fluorescently labelled (red) pentosan polysulfate (TRITC-PPS), then fixed in formalin and fluorescently stained for genetic DNA (blue) and for c-Jun (green) which is one of the key components of AP-1 transcription factor [12]. Fluorescence-labeled NaPPS invaded in to cytoplasm and nucleus (Fig. 3a). The yellow to orange in the overlay image indicates that a

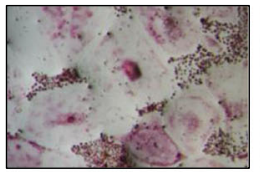

PPS $0 \mu \mathrm{g} / \mathrm{mL}$

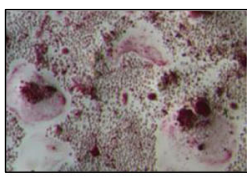

PPS $1 \mu \mathrm{g} / \mathrm{mL}$

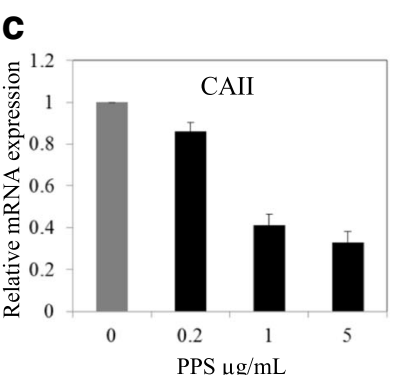

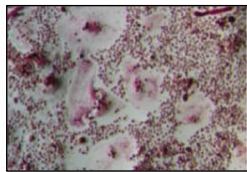

PPS $0.2 \mu \mathrm{g} / \mathrm{mL}$

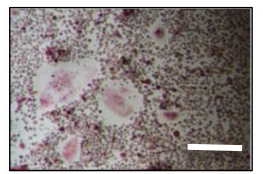

PPS $5 \mu \mathrm{g} / \mathrm{mL}$

\section{b}

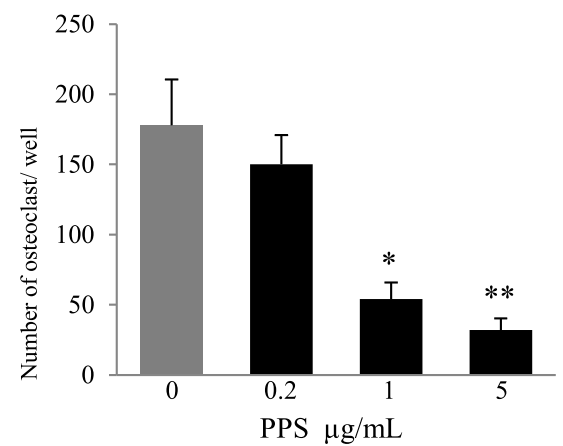

d e
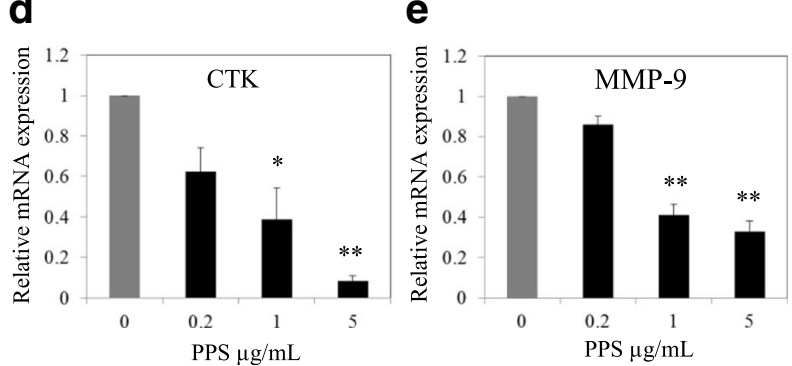

Fig. 1 Shows inhibitory effect of NaPPS on canine OC differentiation. a The cells were treated with various concentration of NaPPS followed by M-CSF $(20 \mathrm{ng} / \mathrm{mL})$ and RANKL $(50 \mathrm{ng} / \mathrm{mL})$ for 7 days. The cells were stained for TRAP stain and $\mathbf{b}$ TRAP-positive cells ( $\geq 3$ nuclei) were counted. Scale bar- $100 \mu \mathrm{m}$. Bar graphs show the concentration effects of NaPPS on mRNA expression levels of $\mathbf{c}$ CA II, $\mathbf{d}$ CTK and e MMP-9 determined by real-time PCR and results were normalized to the expression of GAPDH. Data are representative of five independent experiments and expressed as means \pm SE. Means with *are significantly different from $0 \mu \mathrm{g} / \mathrm{mL}$ of NaPPS $\left({ }^{*} p<0.05,{ }^{* *} p<0.01\right)$ 


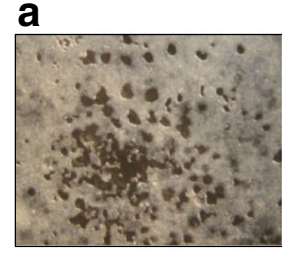

PPS $0 \mu \mathrm{g} / \mathrm{mL}$

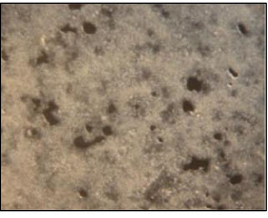

PPS $1 \mu \mathrm{g} / \mathrm{mL}$

b

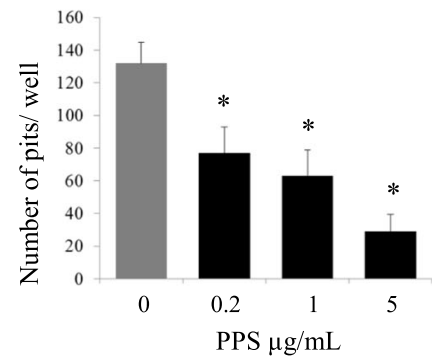

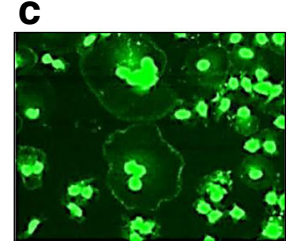

PPS $0 \mu \mathrm{g} / \mathrm{mL}$

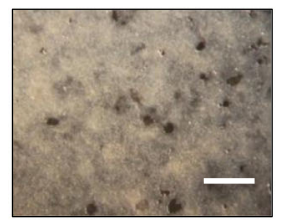

PPS $5 \mu \mathrm{g} / \mathrm{mL}$

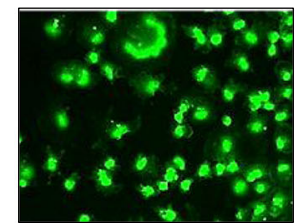

PPS $1 \mu \mathrm{g} / \mathrm{mL}$

d

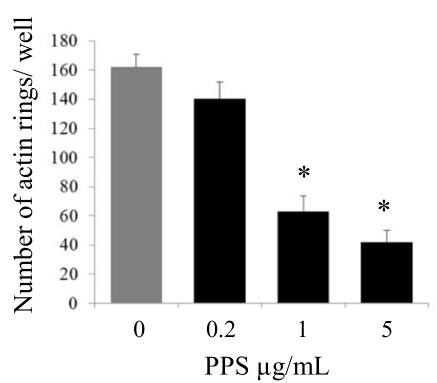

Fig. 2 NaPPS inhibits bone resorption and actin ring formation by concentration gradient. Canine BMMs, cultured with M-CSF ( $25 \mathrm{ng} / \mathrm{mL})$ and RANKL $(50 \mathrm{ng} / \mathrm{mL}$ ) for 7 days with or without indicated doses of NaPPS. a The cells were washed and the resorption pits were counted. $\mathbf{b}$ The numbers of pits were analyzed with Image-J software. c Cells were fixed, stained for F-actin formation (top) and $\mathbf{d}$ osteoclasts with actin ring were counted (bottom). Scale bar- $200 \mu \mathrm{m}$. Column indicates means \pm SE of three experiments performed in triplicate. Means with *are significantly different from $0 \mu \mathrm{g} / \mathrm{mL}$ of NaPPS ( ${ }^{*} p<0.05$ )

NaPPS and c-Jun proteins are in the same location (Fig. 3b). Pentosan inhibits the expression of NFATc1 at 1 and $5 \mu \mathrm{g} / \mathrm{mL}(p<0.05)$ (Fig. 3d, e, f). And decrease c-Fos and AP-1 activation was identified only at concentration of $5 \mu \mathrm{g} / \mathrm{mL}(p<0.05)$. As shown in Fig. 3c, semi quantitative RT-PCR was correlated with quantitative PCR.

\section{Discussion}

In the present study, NaPPS at concentration of $5 \mu \mathrm{g} / \mathrm{mL}$ exerted an inhibitory effect on canine osteoclastogenesis through suppression of key transcription factors such as NFATc1, c-Fos while visualizing co-localization patterns. This information may partially support the suggestion that NaPPS may exert its inhibitory effect on OC by direct interaction with transcription factors, subsequently deterring the target genes like CTK and MMP-9 which are needed in bone resorption activity of OC. To further study the effects of NaPPS on osteoclastogenesis, we examined whether NaPPS affected RANKL-induced OC function by bone resorption assays and actin formation. The results suggested that NaPPS at concentration of 1 and $5 \mu \mathrm{g} / \mathrm{mL}$ suppressed RANKL-induced bone resorption activity and formation of actin-rings of matured OC. The stimulation of M-CSF and RANKL make mature OC result in resorption lacunae, pit formation and actin ring formation [30] which is a prerequisite for OC bone resorption and is the most obvious character of mature OC during osteoclastogenesis [31]. The outcome of this study suggests that the inhibitory action of NaPPS over OC differentiation and function could be applied in treatment of pathological bone disorders where OC play central role.

In this study, the noted inhibition of $\mathrm{OC}$ formation, TRAP activity and density of pits at 1 and $5 \mu \mathrm{g} / \mathrm{mL}$ of NaPPS indicated that an inhibitory effect on osteoclastogenesis and function of mature OC. The commonly used phenotype marker, TRAP is expressed particularly in OC and positive for TRAP stain after pre-OC cells differentiation with the supplement of RANKL [27]. Detection of TRAP-positive cell formation is a renowned method of determining $\mathrm{OC}$ formation and function [32, 33].

In our study, NaPPS at higher concentrations significantly suppressed the NFATc1 up-regulation in OC normally seen with RANKL treatment. In previous knock-out experiments have been demonstrated that NFATc1 [34, 35] and c-Fos are important transcription factors for RANKL-mediated OC differentiation, fusion, and activation [33]. In addition, previous reports demonstrated 

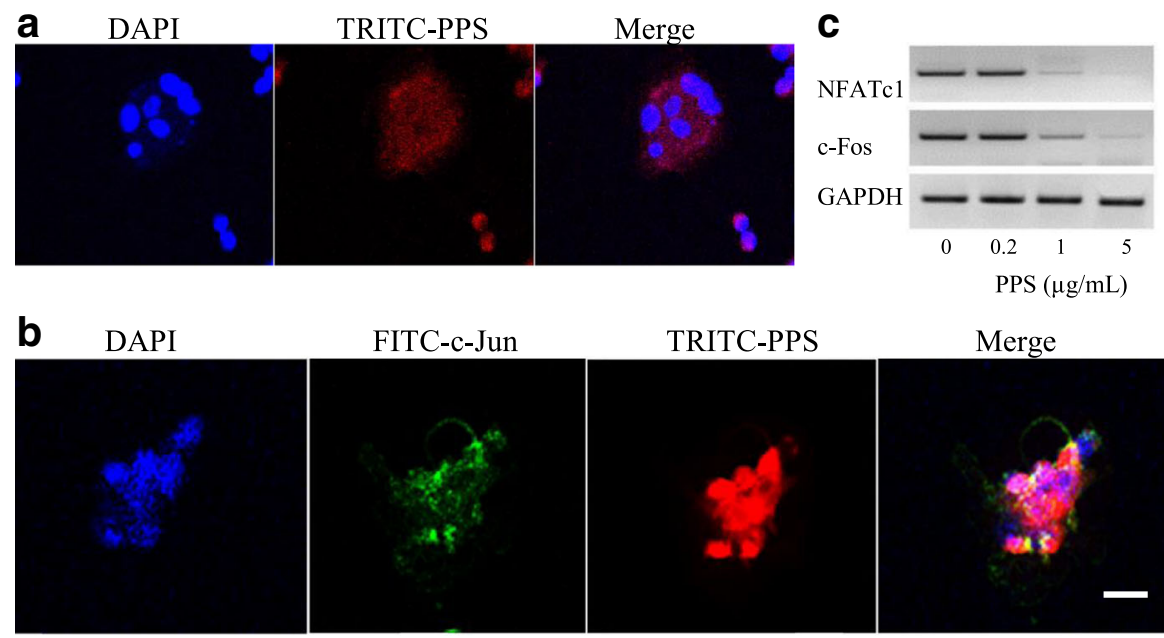

FITC-c-Jun

TRITC-PPS
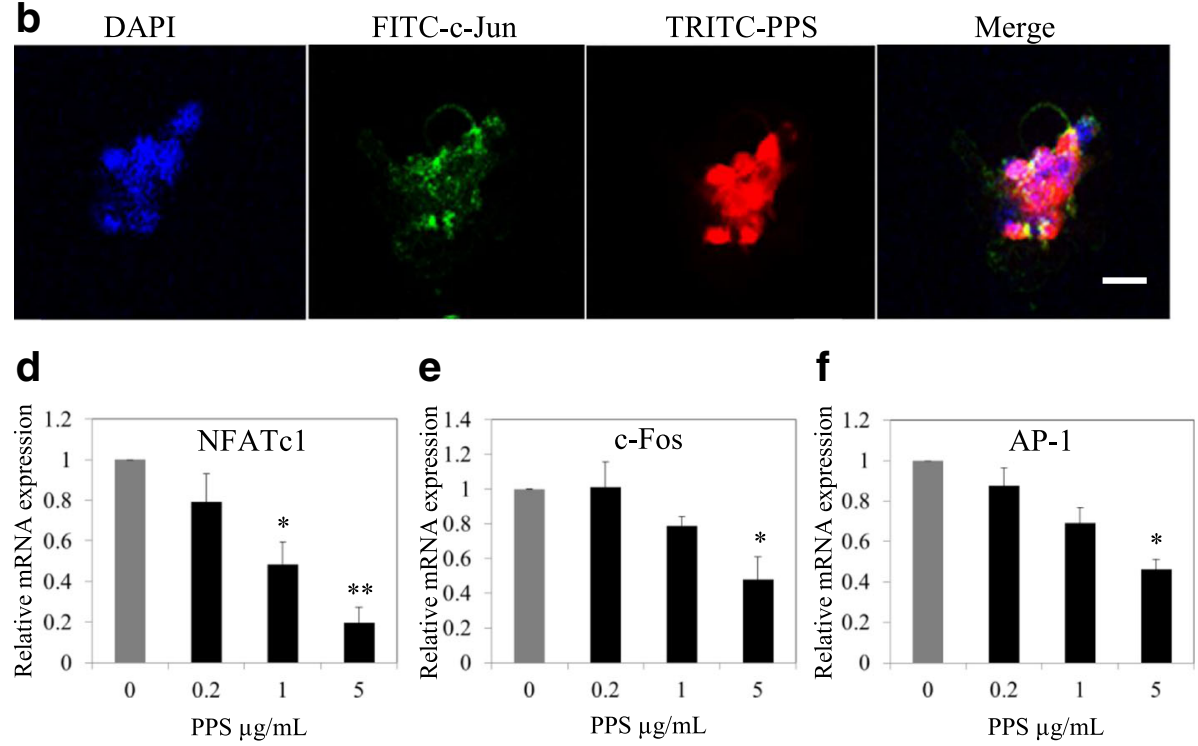

Fig. 3 Inhibitory and co-localization patterns of NaPPS with actively transcribed genes. Osteoclast differentiated from canine bone marrow with supplement of M-CSF ( $25 \mathrm{ng} / \mathrm{mL}$ ) RANKL ( $50 \mathrm{ng} / \mathrm{mL}$ ) together with absence and presence of NaPPS $(0.2,1,5 \mu \mathrm{g} / \mathrm{mL})$ for 7 days was done. a Confocal microscopic images of invasion of TRITC-labeled NaPPS in to osteoclast and $\mathbf{b}$ localization with c-Jun (subunit of AP-1 transcription complex) are shown. The orange in the overlay image indicates that NaPPS and gene activation proteins c-Jun (green) are in the same location. Nuclei were stained with 4,6-diamidino-2-phenylindole dye (DAPI). Scale bar- $100 \mu \mathrm{m}$. c Attenuation effect of NaPPS on master regulators of osteoclastogenesis (NFATc1, c-Fos) by dose dependent pattern are shown. $\mathbf{d}$, e and $\mathbf{f}$ Relative mRNA expression of NFATC1, c-Fos and AP-1 according to the NaPPS concentration gradient was significantly attenuated at $5 \mu \mathrm{g} / \mathrm{mL}$. Data expressed as mean \pm SE for each PPS concentration after normalizing for the expression of the GAPDH. Means with *are significantly different from $0 \mu \mathrm{g} / \mathrm{mL}$ of NaPPS $\left({ }^{*} p<0.05,{ }^{* *} p<0.01\right)$

that NFATc1 is not induced by RANKL stimulation in OC lacking c-Fos [36]. Further, NFATc1 is the master regulator of osteoclastogenesis which is regulated by the AP-1 complex [37]. Dimeric transcription factor, AP-1 is composed of members of the Jun and Fos protein family [38] and has a massive impact on OC differentiation and production of soluble mediators in bone erosion [39].

Intracellular colocalization and interaction of NaPPS with c-Jun transcriptional factor were observed in this study by immunofluorescence assay emphasizing that the site of action of drug of interest. Binding of c-Fos to the NFATc1 promoter is important for its activation [40]. Suppression of NFATc1 by NaPPS is the consequence of the down-regulation of c-Fos, with the subsequent down-regulation of AP-1 activity and attenuation of $\mathrm{OC}$-specific gene expression required for efficient $\mathrm{OC}$ differentiation and bone resorption. Further extension of the study up to detailed work by evaluating specific binding affinity of NaPPS with specific protein at nuclear, sub nuclear domain or nuclear speckles in OC would be much awarded the NaPPS as therapeutic perspective.

Outcome of the present study confirmed that the inhibitory effect of higher concentrations of NaPPS on canine OC differentiation and function, while additional investigations would be required to clarify the mechanism of action of NaPPS on OC in more detail. Although the impact of NaPPS on cell signaling pathways of chondrocytes were well-recognized, invasion in to the $\mathrm{OC}$ and its intracellular reactions, competence of osteoclastogenesis from stem cells and effect on functioning structural formation (actin ring) and transcriptional factors have not been considered until probing by this study. To our knowledge, this is the first study to demonstrate that the inhibitory effect of NaPPS on canine bone marrow-derived $\mathrm{OC}$ differentiation and bone resorption. 


\section{Conclusions}

In this study, we examined the inhibitory effect of NaPPS on in vitro cultured canine $\mathrm{OC}$ differentiation and function stimulated by RANKL and M-CSF. Our findings provide useful preliminary information on the concentration of this drug and should help increase understanding and awareness of the opportunity and or limitation of its therapeutic use among dogs. In particular, the inhibitory effects of NaPPS on CTK, MMP-9, NFATc1, c-Fos and AP-1in OC could translate to it beneficial effects in the prevention of osteoporosis and other bone-erosive diseases such as rheumatoid arthritis and bone diseases associated with excessive bone resorption. Furthermore, our results would be a flat form and promising launch for further investigation to identify the intracellular acting sites of NaPPS and more detailed protein interactions for detailed therapeutic mechanism of action.

\section{Abbreviations}

DMOADs: Disease -modifying osteoarthritis drugs; M-CSF: Macrophage colony-stimulating factor; NaPPS: Sodium pentosan polysulfate; OC: Osteoclast; RA: Rheumatoid arthritis; RANKL: Receptor activator of NF kappa B ligand; TRAP: Tartrate-resistant acid phosphatase

\section{Acknowledgements}

Authors would like to thank Dr. David Cullis-Hill, Arthropharm Pty. Ltd., Australia for providing TRITC-labeled PPS

\section{Availability of data and materials}

The datasets analyzed during the current study available from the corresponding author on reasonable request

\section{Authors' contributions}

SW was responsible for the study concept, design, conducting all experiments, acquisition of data and all the data analysis and drafting of the manuscript. ECB, JF collected, analyzed and interpreted the data. SK, KH was involved in design of study concept, drafting and revising of the manuscript. MO was a major contributor in conception and design of the study, interpretation of data, drafting and revising the manuscript. All authors contributed to the interpretation of the data and approved the final manuscript.

\section{Ethics approval and consent to participate}

The use of clinical samples and all samples from experimental dogs was in accordance with Hokkaido University Institutional Animal Care and Use Committee guidelines (approval number: 12-0059).

\section{Competing interests}

The authors declare that they have no competing interests.

\section{Publisher's Note}

Springer Nature remains neutral with regard to jurisdictional claims in published maps and institutional affiliations.

Received: 14 April 2017 Accepted: 20 April 2018

Published online: 02 May 2018

\section{References}

1. Corral DA, Amling M, Priemel M, Loyer F, Fuchs S, Ducy P, Baron R, Karsenty $G$. Dissociation between bone resorption and bone formation in osteopenic transgenic mice. Proc Natl Acad Sci U S A. 1998;95:13835-40.

2. Karsenty $G$, Wagner EF. Reaching a genetic and molecular understanding of skeletal development. Dev Cell. 2002;2:389-406.

3. Oguro A, Kawase T, Orikasa M. NaF induces early differentiation of murine bone marrow cells along the granulocytic pathway but not the monocytic or preosteoclastic pathway in vitro. In vitro Cell Dev Biol Anim. 2003;39:243-8.
4. Itonaga I, Sabokbar A, Sun SG, Kudo O, Danks L, Ferguson D, Fujikawa Y, Athanasou NA. Transforming growth factor- $\beta$ induces osteoclast formation in the absence of RANKL. Bone. 2004;34:57-64.

5. Boyle WJ, Simonet WS, Lacey DL. Osteoclast differentiation and activation. Nature. 2003;423:337-42.

6. Kim J, Kim E, Lee B, Min J, Song D, Lim J, Eom JW, Yeom M, Jung H, Sohn Y The effects of Lycii Radicis cortex on RANKL-induced osteoclast differentiation and activation in RAW 264.7 cells. Int J Mol Med. 2016;37:649-58.

7. Nakamura I, Takahashi N, Jimi E, Udagawa N, Suda T. Regulation of osteoclast function. Mod Rheumatol. 2012;22:167-77.

8. Nakagawa N, Kinosaki M, Yamaguchi K, Shima N, Yasuda H, Yano K Morinaga T, Higashio K. RANK is the essential signaling receptor for osteoclast differentiation factor in osteoclastogenesis. Biochem Biophys Res Commun. 1998;253:395-400.

9. Wagner EF, Matsuo K. Signalling in osteoclasts and the role of Fos/AP1 proteins. Ann Rheum Dis. 2003;62:83-5.

10. Fujikawa Y, Sabokbar A, Neale S, Athanasou NA. Human osteoclast formation and bone resorption by monocytes and synovial macrophages in rheumatoid arthritis. Ann Rheum Dis. 1996:55:816-22.

11. Itonaga I, Fujikawa Y, Sabokbar A, Murray DW, Athanasou NA. Rheumatoid arthritis synovial macrophage-osteoclast differentiation is osteoprotegerin ligand-dependent. J Pathol. 2000;192:97-104.

12. Yagi M, Miyamoto T, Sawatani Y, Iwamoto K, Hosogane N, Fujita N, Morita K, Ninomiya K, Suzuki T, Miyamoto K, Oike Y, Takeya M, Toyama T, Suda T. DCSTAMP is essential for cell-cell fusion in osteoclasts and foreign body giant cells. J Exp Med. 2005;2020:345-51.

13. Kong YY, Yoshida H, Sarosi I, Tan HL, Timms E, Capparelli C, Morony S, Oliveira-dos-Santos AJ, Van G, Itie A, Khoo W, Wakeham A, Dunstan CR, Lacey DL, Mak TW, Boyle WJ, Penninger JM. OPGL is a key regulator of osteoclastogenesis, lymphocyte development and lymph-node organogenesis. Nature. 1999;397:315-23.

14. Altman R. Measurement of structural modification in osteoarthritis. Osteoarthr Cartil. 2004;12:69-76.

15. Davies NM, Wallace JL. Nonsteroidal anti-inflammatory drug-induced gastrointestinal toxicity, new insights into an old problem. J Gastroenterol. 1997;23:127-33.

16. Ghosh P, Edelman J, March L, Smith M. Effects of Pentosan Polysulfate in osteoarthritis of the knee: a randomized, double-blind, placebo-controlled pilot study. Curr Ther Res. 2005;66:552-71.

17. Kumagai K, Shirabe S, Miyata N, Murata M, Yamauchi A, Kataoka Y, Niwa M. Sodium pentosan polysulfate resulted in cartilage improvement in knee osteoarthritis - an open clinical trial. Clin Pharmacol. 2010; https://doi.org/10. $1186 / 1472-6904-10-7$

18. Burkhardt D, Ghosh P. Laboratory evaluation of antiarthritic agents as potential chondroprotective agents. Semin Arthritis Rheum. 1987:17:3-34.

19. Edelman J, March L, Ghosh PA. Double-blind placebo-controlled clinical study of a pleotropic osteoarthritis drug (pentosan polysulphate Cartrophen v) in 105 patients with osteoarthritis of the knee and hip joints. Osteoarthr Cartil. 1994:2:35.

20. Ghosh P, Smith M, Wells C. Second line agents in osteoarthritis. In: Dixon JS, Furst DE, editors. Second Line Agents in the Treatment of Rheumatic Diseases. New York: Marcel Dekker Inc; 1992. p. 363-427.

21. Ghosh P. The pathobiology of osteoarthritis and the rationale for the use of pentosan polysulfate for its treatment. Semin Arthritis Rheum. 1999;28:211-67.

22. Takizawa M, Yatabe T, Okada A, Chijiiwa M, Mochizuki S, Ghosh P, Okada Y. Calcium pentosan polysulfate directly inhibits enzymatic activity of ADAMTS4 (aggrecanase-1) in osteoarthritic chondrocytes. FEBS Lett. 2008; 582:2945-9.

23. Schumacher HR, Newton C, Halliwell RE. Synovial pathologic changes in spontaneous canine rheumatoid-like arthritis. Arthritis Rheum. 1980;23:412-23.

24. Ghosh P, Wu J, Shimmon S, Zannettino ACW, Gronthos S, Itescu S. Pentosan polysulfate promotes proliferation and chondrogenic differentiation of adult human bone marrow-derived mesenchymal precursor cells. Arthritis Res Ther. 2010;12:28.

25. Bwalya EC, Kim S, Fang J, Wijekoon HMS, Hosoya K, Okumura M. Effects of pentosan polysulfate and polysulfated glycosaminoglycan on chondrogenesis of canine bone marrow-derived mesenchymal stem cells in alginate and micromass culture. J Vet Med Sci. 2017;79(7):1182-90.

26. Marycz K, Smieszek A, Grzesiak J, Nicpon JE. Effects of steroids on the morphology and proliferation of canine and equine mesenchymal stem cells of adipose origin - in vitro research. Acta Vet Hung. 2014;62(3):317-33. 
27. Li F, Chung H, Reddy SV, Lu G, Kurihara N, Zhao AZ, Roodman GD. Annexin II stimulates RANKL expression through MAPK. J Bone Miner Res. 2005;20:1 161-7.

28. MacDonald BR, Takahashi N, McManus LM, Holahan J, Mundy GR, Roodman GD. Formation of multinucleated cells that respond to osteotropic hormones in long term human bone marrow cultures. Endocrinology. 1987;120:2326-33.

29. Hurst R, Zuo J, Holliday LS. Actin-related protein $2 / 3$ complex is required for actin ring formation. J Bone Miner Res. 2004;19:499-506.

30. Jun AY, Kim HJ, Park KK, Son KH, Lee DH, Woo MH, Kim YS, Lee SK, Chung WY. Extract of Magnoliae Flos inhibits ovariectomy-induced osteoporosis by blocking osteoclastogenesis and reducing osteoclast-mediated bone resorption. Fitoterapia. 2012;83:1523-31.

31. Hsu H, Lacey DL, Dunstan CR, Solovyev I, Colombero A, Timms E, Tan HL, Elliott G, Kelley MJ, Sarosi I, Wang L, Xia XZ, Elliott R, Chiu L, Black T, Scully S, Capparelli C, Morony S, Shimamoto G, Bass MB, Boyle WJ. Tumor necrosis factor receptor family member RANK mediates osteoclast differentiation and activation induced by osteoprotegerin ligand. Proc Natl Acad Sci U S A. 1999;96:3540-5.

32. Tanabe N, MaenoM, Suzuki N, Fujisaki K, Tanaka H, Ogiso B, Ito K. IL- 1 alpha stimulates the formation of osteoclast-like cells by increasing M-CSF and PGE2 production and decreasing OPG production by osteoblasts. Life Sci. 2005;77:615-26.

33. Tanaka H, Tanabe N, Shoji M, Suzuki N, Katono T, Sato S, Motohashi M, Maeno M. Nicotine and lipopolysaccharide stimulate the formation of osteoclast-like cells by increasing macrophage colony-stimulating factor and prostaglandin E2 production by osteoblasts. Life Sci. 2006;78:1733-40.

34. Grigoriadis AE, Wang ZQ, Cecchini MG, Hofstetter W, Felix R, Fleisch HA, Wagner EF. C-Fos: a key regulator of osteoclast-macrophage lineage determination and bone remodeling. Science. 1994;226:443-8.

35. Zhao Q, Wang X, Liu Y, He A, Jia R. NFATc1: functions in osteoclasts. Int J Biochem Cell Biol. 2010;42:576-9.

36. Matsuo K, Galson DL, Zhao C, Peng L, Laplace C, Wang KZ, Bachler MA, Amano H, Aburatani H, Ishikawa H, Wagner EF. Nuclear factor of activatedvT-cells (NFAT) rescues osteoclastogenesis in precursors lacking c-Fos. J Biol Chem. 2004;279:26475-80

37. Yagi M, Miyamoto T, Toyama Y, Suda T. Role of DC-STAMP in cellular fusion of osteoclasts and macrophage giant cells. J Bone Miner Metab. 2006;24:355-8.

38. Wagner EF, Eferl R. Fos/AP-1 proteins in bone and the immune system. Immunol Rev. 2005;208:126-32.

39. Zenz R, Eferl R, Scheinecker C, Redlich K, Smolen J, Schonthaler HB, Kenner L, Tschachler E, Wagner EF. Activator protein 1 (Fos/Jun) functions in inflammatory bone and skin disease. Arthritis Res Ther. 2008;10:201.

40. Ghayor C, Correro RM, Lange K, Karfeld-Sulzer LS, KW G't, Weber FE. Inhibition of osteoclast differentiation and bone resorption by N-Methylpyrrolidone. J Biol Chem. 2011:24458-66.

\section{Ready to submit your research? Choose BMC and benefit from:}

- fast, convenient online submission

- thorough peer review by experienced researchers in your field

- rapid publication on acceptance

- support for research data, including large and complex data types

- gold Open Access which fosters wider collaboration and increased citations - maximum visibility for your research: over $100 \mathrm{M}$ website views per year

At BMC, research is always in progress.

Learn more biomedcentral.com/submissions 